\title{
CULTURED HAIR FOLLICLE CELLS FOR THE TREATMENT OF VITILIGO
}

\author{
PIYATIDA SUTNUT ${ }^{1}$, SAROJ SUVANASUTHI ${ }^{2}$, KWANCHANOK VIRAVAIDYA-PASUWAT ${ }^{1 *}$
}

${ }^{1}$ Biological Engineering Program, Faculty of Engineering, KMUTT, Bangkok, Thailand. ${ }^{2}$ Samitivej Esthetics Institute, Samitivej Sukhumvit hospital, Bangkok, Thailand. Email: kwanchanok.vir@kmutt.ac.th

Received: 02 February 2018, Revised and Accepted: 03 October 2018

ABSTRACT

Objective: The objective of this study was to develop a method to isolate cells from hair follicles and cultured them in a hydrogel.

Methods: Different cell types obtained from hair follicles were investigated and mixed with three formulations of Lutrol ${ }^{\circledR}$ F-127-based hydrogels. The percentages of the cell attachment and viability were observed within $48 \mathrm{~h}$.

Results: The results showed that three cell types, including keratinocyte, dermal papilla, and melanocyte cells, were obtained, as shown by the expression of their corresponding genes. All formulations of the hydrogels supported cell attachment and viability. Interestingly, more than $60 \%$ cell attachment and viability were found in lutrol hydrogels supplemented with either fetal bovine serum (FBS) or heat-activated human serum.

Conclusion: Higher cell attachment and viability were observed when the hair follicle cells were cultured in the hydrogel with FBS than the hydrogel with human serum. However, the lutrol gel formulation with human serum was more appropriate to be used in the future clinical study, as this formulation contained no animal-derived component.

Key words: Hair follicles, Hydrogel, Lutrol ${ }^{\circledR}$ F-127, Vitiligo.

(C) 2018 The Authors. Published by Innovare Academic Sciences Pvt Ltd. This is an open access article under the CC BY license (http://creativecommons. org/licenses/by/4. 0/) DOI: http://dx.doi.org/10.22159/ajpcr.2018.v11iS3.30043

\section{INTRODUCTION}

Vitiligo is one kind of human skin diseases caused by the loss of melanocytes or destroyed melanocytes. Melanocytes are cells that are most commonly found in the bottom layer of the skin's epidermis and can produce melanin pigments, resulting in color skin. Melanin is contained in a special organelle called a melanosome. The melanosomes accumulate on top of the nuclear of the epidermis cell, where they protect the nuclear DNA from mutations caused by high levels of exposure to the sun's ultraviolet rays. Vitiligo appears as white lesion on patients' skin as a result of melanin deficiency. Vitiligo affects approximately $0.5 \%-2 \%$ of the world's population [1]. This disease negatively affects not only physical appearance but also the quality of patient's life. The medical cause of vitiligo is still unknown. Most experts agree that the cause is likely to be combination of affected trigger factors (such as hormone changes, oxidative stress, and exposure to some industrial chemicals), genetic inheritance, and autoimmune. Vitiligo cannot to be permanently cured, but the treatments help restore skin color.

Vitiligo can be treated by many treatment options [2] such as narrowband ultraviolet B (NB-UVB), psoralen followed by irradiation with UVA (PUVA), excimer laser, and the epidermal cell transplantation [3]. In Thailand, 308-nm excimer laser is a popular way to treat vitiligo to produce new melanocytes in the skin's epidermis of the patient, but this technique requires melanocytes to remain under the skin of the patients for more than $30 \%$, which may not be suitable for the treatment of vitiligo. Therefore, in patients with stable vitiligo, autologous transplantation technique can be an alternative therapeutic option [4]. This technique is to transplant autologous melanocytes from a normal donor skin to depigmented skin and may be followed by phototherapy NB-UVB after 2-3 weeks of transplantation to stimulate melanocytes. However, this surgical option has a side effect of blister grafting include infection, scarring, and lack normal pigmented skin of repigmentation. Thus, finding new sources of autologous melanocytes for vitiligo treatment are necessary.
An alternative to using dermal melanocytes is to use melanocytes extracted from hair follicles as hair follicles are a rich source of melanocytes, melanocytes precursor cell, and hair follicle melanocytes express some antigens associated with alopecia (hair loss disease) but not antigen associated with vitiligo. However, melanocytes alone are not able to produce melanin. Melanocyte cells and keratinocytes cells have to work together for melanin production. When exposed to sunlight, melanocyte cells activate maturation of melanosome after that melanosome is transported to cell membrane by microtubule. That unique structure called dendrites on surface and then dendrites carries melanosome sent to keratinocyte cells to modify the melanin pigment for skin and hair color [5].

An application of cell solution to the affected area of the skin is often unsuccessful due to the solution running off. To solve this problem, cells from hair follicle were cultured with Lutrol ${ }^{\circledR}$ F127. Lutrol ${ }^{\circledR}$ F-127 is a synthetic hydrogel made of ethylene oxide (PEO) and polypropylene oxide, which is no animal-derived component. This polymer is widely used in pharmaceutical applications and Food and Drug Administration (FDA) approved for its use in humans. Lutrol ${ }^{\circledR}$ F127 hydrogel has thermosensitivity properties due to this hydrogel is a sol-gel transition ability to change from solution stage at low temperature to a viscous gel at high temperature [6]. The thermosensitive properties of Lutrol@ F-127 make it an attractive option for cell culture. However, hair follicle cells have low attachment efficiency and low cell viability when being culture in Lutrol ${ }^{\circledR}$ F127, making the hair follicle cells transplantation not so effective.

In this study, the method to isolate and culture cells from hair follicles was developed. Different cell types obtained from the hair follicle were identified. The lutrol-based hydrogel formulation was modified to improve the cell attachment and viability for future clinical use in vitiligo treatment.

\section{METHODS}

Hair follicles were obtained from discarded hair grafts after hair transplantation surgery. The hair grafts were placed in phosphate- 
Table 1: Oligonucleotide primers used to perform RT-PCR

\begin{tabular}{lll}
\hline Gene & Forward primer sequence (5'-->3') & Reverse primer sequence (5'-->3') \\
\hline GAPDH & GCACCGTCAAGGCTGAGAAC & ATGGTGGTGAAGACGCCAGT \\
Col & AGGGCCAAGACGAAGACATC & AGATCACGTCATCGCACAACA \\
FGF 7 & AGGCAAAGTAAAAGGGACCCA & CAAGAAGCAAAAGGAAGATGAGA \\
ALP & ACAAGCACTCCCACTTCATCTGGA & TCACGTTGTTCCTGTTCAGCTCGT \\
KRT 14 & TGGACGTGAAGACGCGGCTGG & GATTTGGCGGCTGGAGGAGGTC \\
KRT 10 & TGATGTGAATGTGGAAATGAATGC & GTAGTCAGTTCCTTGCTCTTTTCA \\
Tyrosinase & CCTCTCAAAGCAGCATGCACAAT & GACGACACAGCAAGCTCACAAG \\
MITF-M & TTATAGTACCTTCTCTTTGCCAGTCC & GTTTATTTGCTAAAGTGGTAGAAAGGTACT \\
\hline
\end{tabular}

RT-PCR: Reverse transcriptase-polymerase chain reaction, ALP: Alkaline phosphatase, FGF 7: Fibroblast growth factor-7, MITF-M: Microphthalmia-associated transcription factor

Table 2: Components in each formulation

\begin{tabular}{|c|c|c|c|c|c|}
\hline Formulation & $\begin{array}{l}\text { Number of } \\
\text { cells }\left(\text { cell } / \mathrm{cm}^{2}\right)\end{array}$ & $\begin{array}{l}\text { Lutrol }^{\circledR} \\
\text { F-127 (\%) }\end{array}$ & FBS (\%) & $\begin{array}{l}\text { Human } \\
\text { serum }(\%)\end{array}$ & $\begin{array}{l}\text { Normal } \\
\text { saline (\%) }\end{array}$ \\
\hline F1 & 5,000 & 18 & 0 & 0 & 82 \\
\hline F2 & 5,000 & 18 & 10 & 0 & 72 \\
\hline F3 & 5,000 & 18 & 0 & 10 & 72 \\
\hline
\end{tabular}

Table 3: Numbers of the cells isolated from one hair follicle using the two isolation techniques

\begin{tabular}{ll}
\hline $\begin{array}{l}\text { Enzymatic disaggregation } \\
\text { (cells/one hair follicle) }^{\mathrm{a}}\end{array}$ & $\begin{array}{l}\text { Mechanical disaggregation } \\
\text { (cells/one hair follicle) }^{\mathrm{a}}\end{array}$ \\
\hline $3.200 \pm 665.83$ & $2.800 \pm 692.82$ \\
\hline${ }^{\mathrm{a} M e a n} \pm \mathrm{SD}, \mathrm{n}=3$ &
\end{tabular}

Table 4: The result of cell attachment and cell viability

\begin{tabular}{lll}
\hline Formulation & $\begin{array}{l}\text { Percent of cells } \\
\text { attachment }(\mathbf{\%})^{\mathbf{a}}\end{array}$ & $\begin{array}{l}\text { The percentages } \\
\text { of live cells } \mathbf{( \% )}^{\mathbf{a}}\end{array}$ \\
\hline F1 & $23.47 \pm 3.47$ & $45.04 \pm 2.88$ \\
F2 & $71.36 \pm 2.84$ & $88.95 \pm 1.52$ \\
F3 & $64.55 \pm 7.73$ & $86.21 \pm 2.72$ \\
\hline${ }^{a}$ Mean \pm SD, $n=3$ & &
\end{tabular}

buffered saline (PBS) solution and transported to the laboratory under sterile condition.

\section{Isolation and culture of the cells from hair follicles} Enzymatic disaggregation

The hair follicles (discarded surgical tissue) were washed 3 times with PBS. The hair follicles were incubated with $0.25 \%$ trypsin- $0.05 \%$ ethylenediaminetetraacetic acid (Invitrogen, Canada) in a shaking incubator at $37^{\circ} \mathrm{C}$ for $90 \mathrm{~min}$ to prepare single cell suspension. Trypsin was neutralized with the culture medium containing melanocyte growth medium-4 (MGMTM-4 Bulletkit, Lonza, MD, USA) supplemented with endothelin 3 (ET3, Lonza, MD, USA), 10\% fetal bovine serum (FBS, Gibco, USA), and 1\% penicillin/streptomycin (Invitrogen Corporation, USA). The cell suspension was centrifuged for $5 \mathrm{~min}$ at $1500 \mathrm{rpm}$. The cell pellet was resuspended in $500 \mu \mathrm{L}$ medium and the cells were counted with a hemocytometer. The culture was incubated at $37^{\circ} \mathrm{C}$ in a humidified atmosphere of $5 \% \mathrm{CO}_{2}$ in air.

\section{Mechanical disaggregation}

The hair follicles were washed with PBS. After washing, the hair follicles were placed in a sterile Petri dish. Hair follicles were cut with a sterile scalpel. The cells were extracted from the hair follicles by applying gentle pressure with a piston of a disposable plastic syringe (sieving method) and then the cell solution was placed in a shaking incubator at $37^{\circ} \mathrm{C}$ for $90 \mathrm{~min}$. The cell suspension was centrifuged for $5 \mathrm{~min}$ at $1500 \mathrm{rpm}$. The cell pellet was resuspended in $500 \mu \mathrm{L}$ medium and the cells were counted with a hemocytometer. The cells were cultured in melanocyte growth medium-4 (MGMTM-4 Bulletkit, Lonza, MD, USA) supplemented with endothelin 3 (ET3, Lonza, MD, USA), 10\% FBS (FBS, Gibco, USA), and 1\% penicillin/streptomycin (Invitrogen Corporation, USA) and incubated at $37^{\circ} \mathrm{C}$ in a humidified atmosphere of $5 \% \mathrm{CO}_{2}$ in air.

Reverse transcriptase-polymerase chain reaction (RT-PCR) mRNA was extracted from cell culture (RNeasy mini kit, Qiagen, Germany). cDNA was synthesized by applying SuperScript ${ }^{\circledR}$ III First-Strand Synthesis System for RT-PCR (Invitrogen ${ }^{\mathrm{TM}}$, USA). PCR (35 cycles) was performed with KAPA Taq ReadyMix PCR kit with dye (Kapa - Biosystems, South Africa) using $20 \mathrm{ng} / \mu \mathrm{L}$ of each primer and gene-specific primers as listed in Table 1 . The internal control was glyceraldehyde 3-phosphate dehydrogenase (GADPH) throughout the experiments.

\section{Gel formulations and cell attachment measurement}

Lutrol ${ }^{\circledR}$ F-127 (BASF, North America; Poloxamer 407) was slowly added to normal saline to make a $30 \%(\mathrm{~W} / \mathrm{V})$ stock solution. The Lutrol ${ }^{\circledR}$ F-127 solution was continuously stirred using a magnetic stirrer on ice for overnight. The F-127 solution was sterilized by autoclave. The Lutrol $^{\circledR}$ F-127 stock solution was stored in a refrigerator until use. To culture the cell in Lutrol $^{\circledR}$ F-127, the ratios of Lutrol ${ }^{\circledR}$ F-127, FBS, human serum, and normal saline were studied as shown in Table 2 . Hair follicle cells at a density of 5,000 cells $/ \mathrm{cm}^{2}$ were mixed with each hydrogel formulation in a liquid form at $4^{\circ} \mathrm{C}$. The homogeneous mixture was added to each well into 48 -well plates. After incubation at $37^{\circ} \mathrm{C}$ in a humidified atmosphere of $5 \% \mathrm{CO}_{2}$ for $48 \mathrm{~h}$, the cell-gel mixture was washed 3 times with cold normal saline. Cell morphology was observed by Cytell Cell Imaging System (GE Healthcare Life science, Pittsburg, PA) at $\times 10$ magnification, and the cell number was counted by Katikati counter program at $48 \mathrm{~h}$.

To calculate the cell attachment, the following equation formula was used:

$$
\text { Cell attachmentpercentage }=\frac{\begin{array}{l}
\text { Amount of cells on } \\
\text { the tissue culture plate }
\end{array}}{\begin{array}{l}
\text { Total amount of cells } \\
\text { on one tissue culture plate }
\end{array}} \times 100
$$

\section{Cell viability test}

A LIVE/DEAD ${ }^{\circledR}$ assay kit (Invitrogen, USA) was utilized to assess the viability of the cell attachment in Lutrol F-127 hydrogel after $48 \mathrm{~h}$. The 

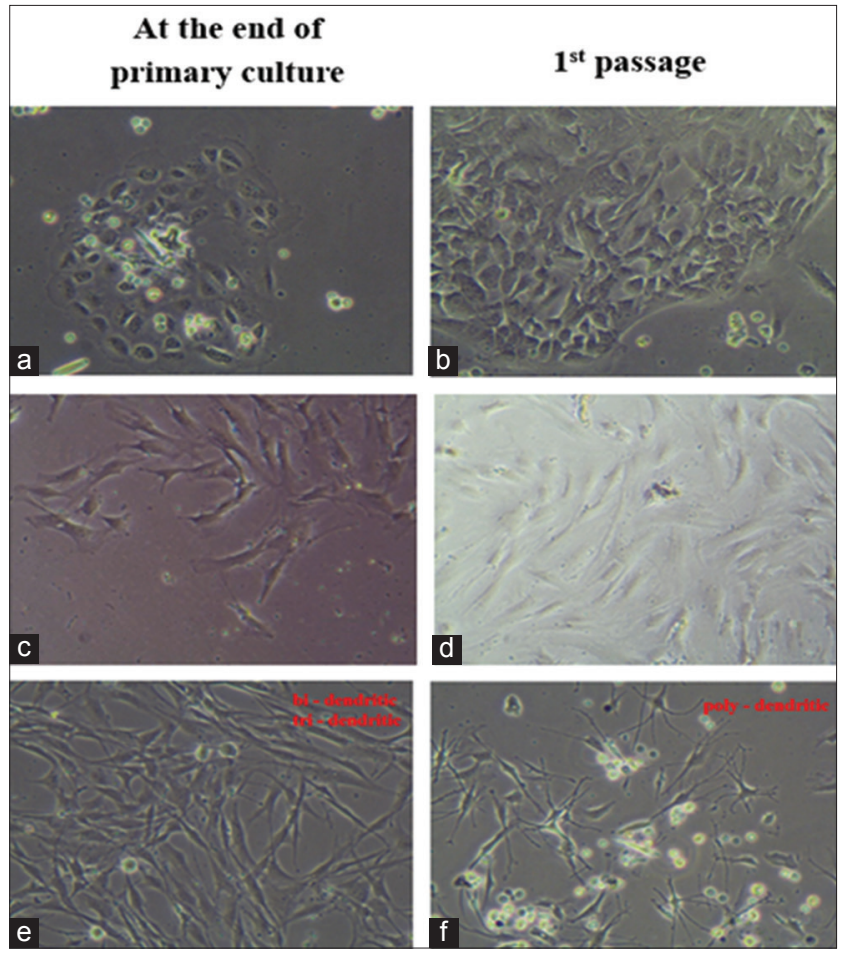

Fig. 1: Morphologies of primary hair follicle cell culture containing (a) keratinocytes, (b) dermal papilla cells, and (c) melanocytes

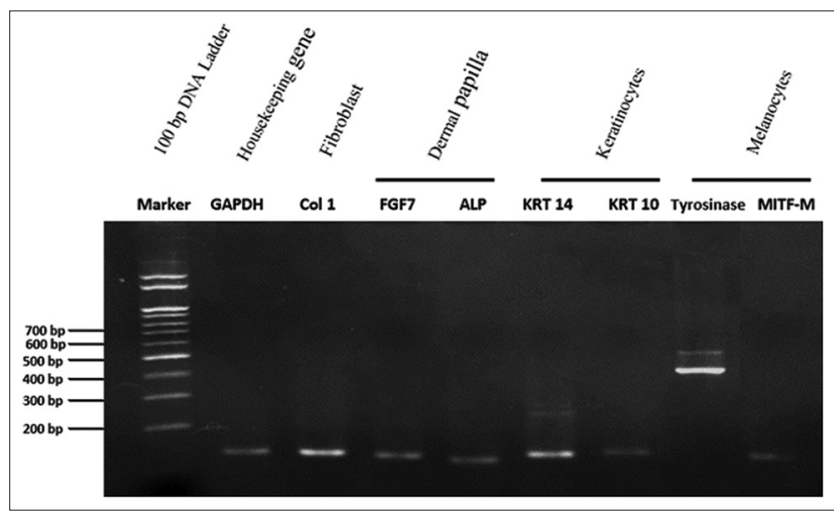

Fig. 2: Reverse transcriptase-polymerase chain reaction (PCR) analysis of mRNA. mRNA was extracted from primary culture of hair follicle at passage 3 . After reverse transcription, resulting cDNA was subjected to 35 cycles PCR using specific primer for GAPDH (142bp), Col (138bp), fibroblast growth factor (FGF) (135bp), alkaline phosphatase (126bp), KRT14 (140bp), KRT10 (147bp), tyrosinase (435bp), and microphthalmiaassociated transcription factor (146bp) samples were examined under a fluorescence microscope of Cytell system (GE Healthcare Life science, Pittsburg, PA). The specimens were examined and the numbers of green (live) and red (dead) cells were counted in each sample. The percentages of live cells and dead cells were determined from five independent specimens for each experimental group using the ImageJ program (version 1.41, NIH, USA).

\section{RESULTS AND DISCUSSION}

\section{Morphology of the cell culture}

After trypsinization of hair follicle and cell culture by Melanocyte Growth Medium-4 (MGMTM-4 Bulletkit, Lonza, MD USA) with supplement, the result at the end of primary cell culture showed three cell types including keratinocytes, dermal papilla cells, and melanocytes (Fig. 1). The morphologies of the cells were studied by an inverted optical microscope (bright field). Human hair follicle keratinocytes consisted of relatively large cuboidal cells with dark nuclei. Dermal papilla cells were highly specialized fibroblasts. Those cells appeared as a lattice of densely packed, small and thin cells. Hair follicle melanocytes under a bright field microscopy had morphologically large cell bodies with dendrite. At the end of the primary culture, the cells' morphology changed to bidendritic and tridendritic. This morphology was melanoblast and amelanotic property (amelanotic is mean without melanin). In the first passage, melanocytes had a polydendritic feature, which allowed the cells to produce pigment [7].

\section{Numbers of cells in hair follicles}

Our previous result showed that the MGMTM-4 Bulletkit with supplement was effective in cell isolation from hair follicles. The cells were isolated from hair follicles using either enzymatic disaggregation or mechanical disaggregation. Although enzymatic disaggregation was commonly used in primary cell isolation, the use of enzyme affected the membrane protein which could lead to lower cell attachment. Therefore, the mechanical disaggregation technique was proposed. In this study, we compared the effectiveness of these two methods in the cell isolation from hair follicles. It was found that a higher cell number was isolated from one hair follicle using the mechanical disaggregation technique, as compared to the enzymatic disaggregation technique (Table 3). This experiment counted the total number of cells in one hair follicle. We compared the cell numbers obtained from mechanical disaggregation technique and enzymatic disaggregation technique. Cell suspension of mechanical disaggregation contained about $2.800 \pm 692.82$ cells per one hair follicle and enzymatic disaggregation gave cell suspension about $3.200 \pm 665.83$ cells per one hair follicle (Table 3). Enzymatic disaggregation of tissues is more efficient. This is due to the presence of less fibrous connective tissue and extracellular matrix. Enzymatic disaggregation can be carried out using trypsin enzymes. Although the number of cells obtained from mechanical techniques was lower than the enzymatic techniques, the mechanical disaggregation technique should also be considered. Mechanical disaggregation basically involves careful chopping and collection of cells. Mechanical method is less expensive, quick, simple, and approved by the U.S. FDA for use in clinical applications.

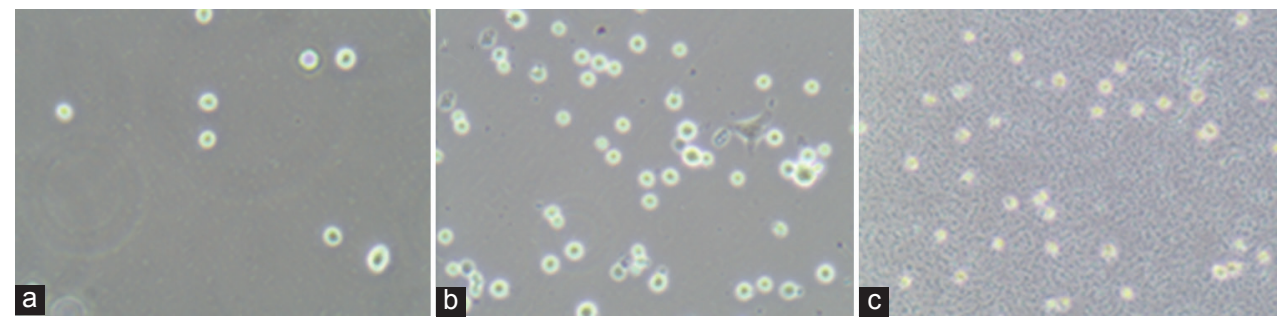

Fig. 3: Cell morphology of formulation (a) F1, (b) F2, and (c) F3 

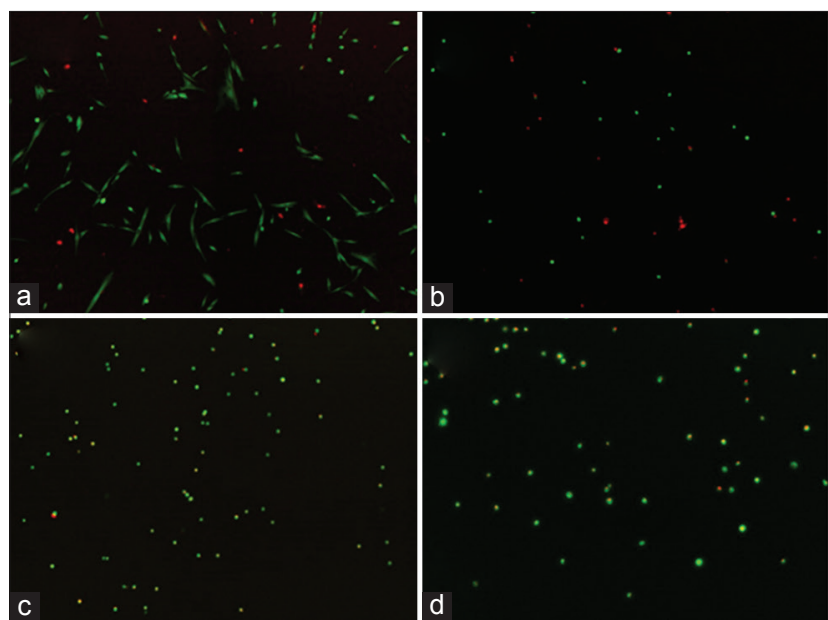

Fig. 4: Viable cells were stained with LIVE/DEAD ${ }^{\circledR}$ assay kit cultured in (a) MBM-4 medium (91.43 $\pm 1.07 \%$ ), (b) formulation F1 (45.04 $\pm 2.88 \%)$, (c) formulation F2 $(88.95 \pm 1.52 \%)$, and formulation F3 $(86.21 \pm 2.72 \%)$ at $48 \mathrm{~h}$

\section{RT-PCR}

After isolation, we experimentally confirmed the detection of the genes in primary cell culture by RT-PCR (Fig. 2).

GAPDH housekeeping gene detection was shown as a positive control in experiment. The end point RT-PCR demonstrated that primary cell culture consisted fibroblast, dermal papilla, keratinocytes, and melanocytes. Collagen type 1 gene expression was expressed in dermal fibroblasts [8] which had been cultured from the region between hair follicles and dermis. Dermal papilla cells expressed ALP and FGF7. The ALP is related to the activity to induce hair follicle formation and has been used as marker molecules for dermal papilla cells. Keratin 10 (KRT10) and keratin 14 (KRT14) were produced in keratinocytes cells in hair follicle [9]. The gene expression of melanocytes cells was tyrosinase and melanocytes-specific microphthalmia-associated transcription factor isoform (MITF-M). These cells expressed several pigment cell-specific genes that have been activated by MITF-M and tyrosinase. Tyrosinase gene was only present in cells expressing several pigments [10].

\section{Cell attachment analysis}

Lutrol ${ }^{\circledR}$ F127 hydrogel was used at a concentration of $18 \%$. Lutrol ${ }^{\circledR}$ F127 was not able to form a gel at a concentration lower than $15 \%$. Therefore, this concentration was not appropriate to be used in real clinical applications. Concentrated solutions of Lutrol ${ }^{\circledR} \mathrm{F} 127$ in aqueous media $(18-20 \% \mathrm{w} / \mathrm{v})$ solidified so quickly at room temperature and formed gel at physiological temperature, $37^{\circ} \mathrm{C}$, which would be practical to be used in real clinical setting. The amount of FBS used in formulation $\mathrm{F} 2$ was $10 \%$ due to this concentration used in typical cell culture (Table 4). The amount of human serum used in formulation F3 was $10 \%$ to be similar to the concentration of FBS (Table 4). Normal saline was used as a diluent. In this experiment, the cell culture and the gel formulation were mixed at $4^{\circ} \mathrm{C}$.

The cell attachment in formulation $\mathrm{F} 1$ was $23.47 \pm 3.47 \%$ at $48 \mathrm{~h}$. The cells were flattened but not spread because Lutrol ${ }^{\circledR}$ F127 had an effect on the viscosity. Formulation F1 in the Lutrol ${ }^{\circledR}$ F127 without FBS was used as negative control in this experiment. Formulation F2 and F3 showed higher percent cell attachment increases to $71.36 \pm 2.84 \%$ and $64.55 \pm 7.73 \%$, respectively, at $48 \mathrm{~h}$ (Fig. 3).

The results revealed that FBS was an important component for cell culture affecting cell growth. However, FBS was an animal-derived product, which could not be used in human body for clinical setting. From this situation, we used human serum due to its more compatibility with the human body.

\section{Cell viability}

LIVE/DEAD ${ }^{\circledR}$ assay kit (Invitrogen, USA) was used to determine viable cells present in a cell culture with different gel formulations after 48 h. Calcein AM showed green color in live cells because calcein AM was hydrolyzed by esterases enzyme in live cells to yield a green color product. Ethidium homodimer 1 (EthD-1) showed red color in dead cells. EthD-1 could diffuse into dead cells through broken plasma membrane to bind with DNA and nuclei in cells, showing red color.

The percentages of live cells and dead cells were determined from images of cells each experimental group using ImageJ software. The cell viability was $91.43 \pm 1.07 \%, 45.04 \pm 2.88 \%, 88.95 \pm 1.52 \%$, and $86.21 \pm 2.72 \%$ for the control which was a monolayer cultured in MBM-4 medium, formulation F1, formulation F2, and formulation F3, respectively (Table 4 and Fig. 4).

\section{CONCLUSION}

In this study, we developed a method to isolate melanocytes cells from hair follicles. The trypsinization was used in the isolation of melanocytes from hair follicles. MBM-4 medium with supplement was selected as a melanocyte isolation medium. The enzymatic disaggregation technique yielded a higher number of cells extracted from hair follicles as compared to the mechanical disaggregation technique. The gene expression from RT-PCR from the hair follicle cell culture indicated that the hair follicle culture consisted of fibroblast, dermal papilla, keratinocytes, and melanocytes. Afterward, the hair follicle cells were cultured in Lutrol ${ }^{\circledR}$ F127-based hydrogels for $48 \mathrm{~h}$. The highest cell attachment percentage was observed in hydrogel formulation with FBS (F2), followed by the gel formulation with human serum (F3). In the gel formulation without serum (F1), both cell attachment and cell viability were the lowest, as serum was an important component for cell growth. Although the gel formulation with FBS (F2) yielded the highest cell attachment and cell viability, the gel formulation (F3) was more appropriate to be used in real clinical setting as it is more compatible with the human body.

\section{CONFLICTS OF INTEREST}

All authors declare that they have no conflicts of interest.

\section{REFERENCES}

1. Alzolibani AA, Al Robaee A, Zedan K. Genetic epidemiology and heritability of vitiligo. Acta Dermatovenerol Alp Pannonica Adriat 2011;3:74

2. Lakhani DM, Deshpande AS. Various treatments for vitiligo: Problems associated and solutions. J Appl Pharm Sci 2014;4:101-5.

3. Majid I. Does topical tacrolimus ointment enhance the efficacy of narrowband ultraviolet B therapy in vitiligo? A left-right comparison study. Photodermatol Photoimmunol Photomed 2010;26:230-4

4. Singh C, Parsad D, Kanwar AJ, Dogra S, Kumar R. Comparison between autologous noncultured extracted hair follicle outer root sheath cell suspension and autologous noncultured epidermal cell suspension in the treatment of stable vitiligo: A randomized study. Br J Dermatol 2013;169:287-93.

5. Hirobe T. Keratinocytes regulate the function of melanocytes. Dermatol Sinica 2014;32:200-4

6. Diniz IM, Chen C, Xu X, Ansari S, Zadeh HH, Marques MM, et al. Pluronic F-127 hydrogel as a promising scaffold for encapsulation of dental-derived mesenchymal stem cells. J Mater Sci Mater Med 2015;26:153.

7. Na GY, Paek SH, Park BC, Kim DW, Lee WJ, Lee SJ, et al. Isolation and characterization of outer root sheath melanocytes of human hair follicles. Br J Dermatol 2006;155:902-9.

8. Sorrell JM, Caplan AI. Fibroblast heterogeneity: More than skin deep. J Cell Sci 2004;117:667-75.

9. Borowiec AS, Delcourt P, Dewailly E, Bidaux G. Optimal differentiation of in vitro keratinocytes requires multifactorial external control. PLoS One 2013;8:e77507.

10. Vetrini F, Auricchio A, Du J, Angeletti B, Fisher DE, Ballabio A, et al. The microphthalmia transcription factor (Mitf) controls expression of the ocular albinism Type 1 gene: Link between melanin synthesis and melanosome biogenesis. Mol Cell Biol 2004;24:6550-9. 